\title{
Construction and Evaluation of the index system for National Garden City DELIGEER ${ }^{1, a}$, LI Yuan-yuan ${ }^{1, b}$
}

\author{
${ }^{1}$ College of Agriculture Science, Inner Mongolia Nationalities University, Tongliao 028043, Inner \\ Mongolia, China \\ a394063476@qq.com, b59556679@qq.com,
}

Keywords: Garden City; index system; screening; evaluation;

\begin{abstract}
The existing national garden city assessment standard mainly uses the method of the qualitative evaluation, the means is unitary, makes the appraisal result to lack the scientific and the authority.Aiming at this problem, this study on the basis of the existing standard proposed the combination of subjective and objective, qualitative and quantitative modeling method, constructing national garden city evaluation index system and the use of expert selection, statistical screening method, the system can better reflect the actual situation, to make up for the deficiencies in the existing standards, has a certain feasibility.
\end{abstract}

\section{Introduction}

With the expansion of city size and population increase, environmental pollution and social order problems have become increasingly prominent, how to solve the problem of "urban disease" in the process of urbanization development, efforts to improve the quality of ecological environment construction is particularly important[1][2]. Garden city is an urban model with Chinese characteristics; it is to further promote the development of urban landscape greening, to promote the construction of the ecological environment, to guide the city to the urban ecological steady development of construction mode. Create a garden city is to speed up the urban infrastructure, improve the level of urban construction and management, improve the quality of life of the residents and city image as an important carrier, to enhance the city's awareness, promote urbanization and regional economic sustainable development, building a harmonious society has an irreplaceable important role.

In the existing national garden city standards, did not take into account the landscape quality and ecological environment construction index content, is difficult to comprehensive and objective reflect urban greening construction, the lack of standardized evaluation basis[3].

Based on the standard of original national garden city, this paper constructs and optimizes the evaluation index system of national garden city by using subjective and objective, qualitative and quantitative method. At the same time, Hohhot and other six cities as the research object, according to the city's own characteristics and the different regions to determine the index weight formulated corresponding evaluation index and grade evaluation[4][5]. After the screening evaluation index, build the final evaluation index system of national garden city.

\section{Characteristics of the garden city}

Garden city not only requires strengthening the construction of ecological and landscaping, more important is to must promote economic development, social progress, constantly enhance urban functions. City itself is an artificial ecosystem, the key to realize a virtuous cycle is how to make the human economic activities and the environment coordination, social management is conducive to the sustainable development. Garden city should have the following features; 


\section{Ornamental}

Emphasize landscape green nature beauty and ecological beauty, the beauty of nature combined with garden, garden, associated with construction and its function, will give people a new feeling and enjoyment, can adjust the mood, edify sentiment. In addition, you can from the city of nature, the humanities, arts, etc., the development and utilization of natural factors, value creation and accumulation of urban cultural landscape.

\section{Ecology}

Garden city should not only have good natural ecological system, low environmental pollution, urban greening, and perfect the system of natural resources can be recycled. On the basis of strengthening landscape, pay more attention to the ecosystem. Reasonable urban planning and construction, realize the people-centered the virtuous cycle of biological systems, so as to maintain the ecological balance, improve the comfort city environment.

\section{Regional}

Between rural and urban areas is mutual connection and restriction, only has the potential to be balance the coordinated development of regional balance coordination of ecological city. Therefore, garden city is established on the basis of regional balanced development, show the obvious regional characteristics.

\section{Construction and optimization of the index system for garden city}

Screening method of evaluation index. In the process of the evaluation of garden city, the evaluation index has the scientific and reasonable index, so it is necessary to optimize the evaluation index. It is not scientific to select the evaluation index by subjective method or objective statistical method. This article comprehensively by combining subjective and objective combination, screening and quantitative and qualitative analysis method for screening index, both to ensure the screened index in the criterion layer on the evaluation result, and avoid the repeat the same index information.

\section{Qualitative index selection method}

Using Pearson $\chi^{2}$ statistics based on correlation coefficient matrix of principal component analysis (PCA), factor analysis and based on this, according to the factor loading matrix of principal component and the absolute value of correlation coefficient of the size of each original index for the choice of original indicators. Set $x$ and $y$ are random variables, $x_{i}, y_{j}$ represent different state, And meet $i=1,2,3 \cdots k ; j=1.2 .3 \cdots r$,can be represented with a specified number or letters and so on, for $\mathrm{n}$ different samples, can calculate the frequency of $x=x_{i}$ or $y=y_{j}$, the model can be represented as[6]:

$$
\chi^{2}=\sum_{i=1}^{k} \sum_{j}^{r} \frac{\left(n m-\sum_{j=1}^{r} m \sum_{i=1}^{k} m\right)^{2}}{n \sum_{j=1}^{r} m \sum_{i=1}^{k} m}
$$

2. Quantitative index screening method

In this paper, correlation analysis method for quantitative indicators of screening, evaluation of a larger number of garden city, there are many indicators correlated to some extent, so that the observations reflected in a large number of overlapping information. The purpose is to evaluate the correlation analysis indicators highly relevant indicators in order to eliminate the impact of the comprehensive evaluation index system to reduce the number of indicators. First evaluation dimensionless and consistent treatment, then calculate simple correlation coefficient between $R_{i j}$ each evaluation, if the coefficient is greater than a predetermined threshold value $K(0<K<1)$, can 
be important indicators according to remove one of evaluation, if less than the critical value, while retaining the two evaluation indexes.

The optimization and screening process of the evaluation index. The main methods of this paper are: expert consultation method, principal component analysis and correlation analysis, as shown in Figure 1.

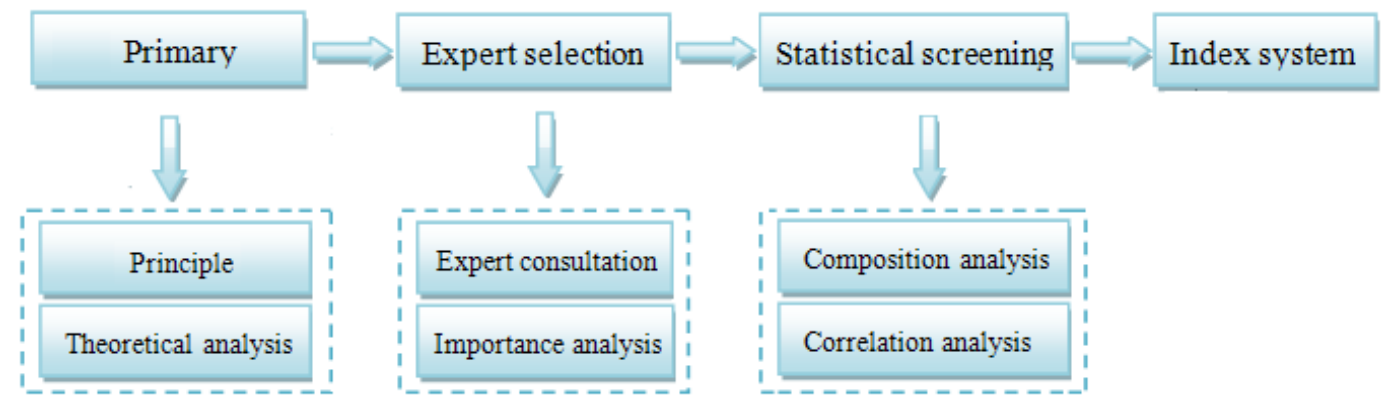

Fig.1 screening process of evaluation index

Primary index. Follow the index system of the general principles of constructing screened including landscape quantity, garden green land quality, municipal infrastructure and ecological environment construction, including four level evaluation index, the level indicators for further refinement, divided into 57 second grade indexes, the initial construction of garden city evaluation index system model, as shown in Figure 2.

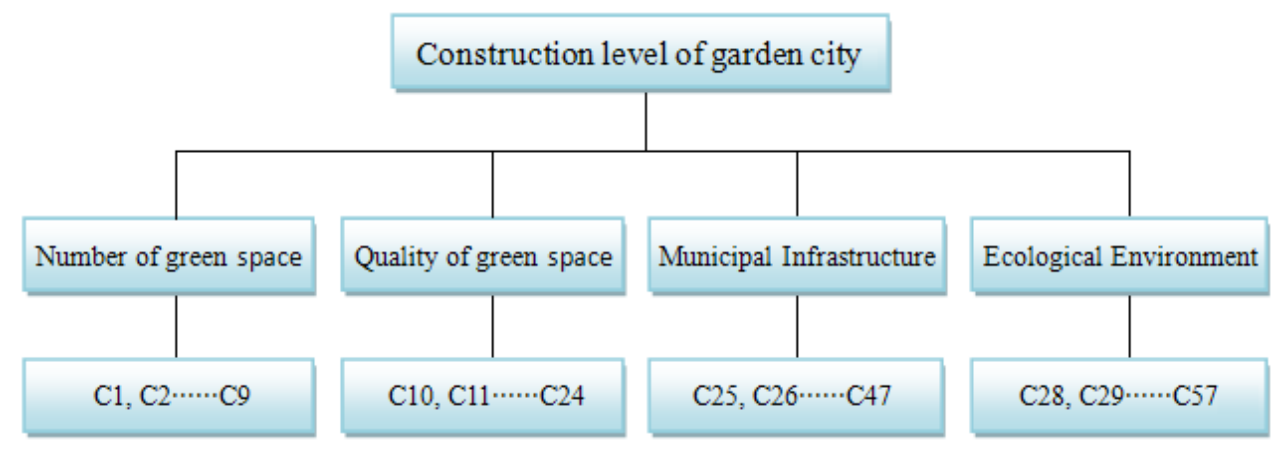

Fig. 2 model of evaluation index system

The number of gardens and green by green coverage rate, public green area, 9 second level indicators, $\mathrm{B} 1=\{\mathrm{CI}, \mathrm{C} 2 \cdots \mathrm{C} 9\}$ said; Greenland quality by the kinds of trees, garden plant survival rate of 15 secondary indicators, $\mathrm{B} 2=\{\mathrm{C} 10, \mathrm{C} 11 \cdots \mathrm{C} 24\}$ said; municipal infrastructure by infrastructure intact rate, sewage treatment compliance rate of 23 second level indicators, $B 3=\{C 25$, C26‥C47\} said; ecological environment construction by the environmental noise, water quality compliance rate of 10 secondary indicators, B4 $=\{C 48, C 49 \cdots$ C57 $\}$ said.

Expert selection. With reference to the general index of classification method, by way of questionnaire to solicit experts and scholars in related fields to all primary target classification, and according to the important degree of scoring important - 3 points, general 2 points, not important 1 ), according to the feedback from the expert, the data were statistical processing and analysis, the experts agree that no important index delete and were then screened for the next step.

Statistical screening. Screening results according to the experts, the indexes of optimization and screening, due to B1, B4 index in the remaining indicators less and are in line with the actual evaluation requirements, so here only to the B2, B3 index screening.

1. Principal component selection of $\mathrm{B} 2$

Select 5 levels, namely: $\{\mathrm{A}, \mathrm{B}, \mathrm{C}, \mathrm{D}$, and $\mathrm{E}\}=\{$ is good, good, general, poor, and very bad $\}$, respectively, 15 of the $\mathrm{B} 2$ indicators were evaluated, the results of the assessment shown in Table 1. 
Tab.1 assessment of landscape green space construction quality level

\begin{tabular}{|c|c|c|c|c|c|c|c|c|c|c|c|c|c|c|}
\hline $\mathrm{X} 1$ & $\mathrm{X} 2$ & $\mathrm{X} 3$ & $\mathrm{X} 4$ & $\mathrm{X} 5$ & $\mathrm{X} 6$ & $\mathrm{X} 7$ & $\mathrm{X} 8$ & $\mathrm{X} 9$ & $\mathrm{X} 10$ & $\mathrm{X} 11$ & $\mathrm{X} 12$ & $\mathrm{X} 13$ & $\mathrm{X} 14$ & $\mathrm{X} 15$ \\
\hline D & $\mathrm{B}$ & $\mathrm{B}$ & $\mathrm{C}$ & $\mathrm{D}$ & $\mathrm{B}$ & $\mathrm{A}$ & $\mathrm{A}$ & $\mathrm{E}$ & $\mathrm{B}$ & $\mathrm{C}$ & $\mathrm{B}$ & $\mathrm{B}$ & $\mathrm{C}$ & $\mathrm{B}$ \\
\hline $\mathrm{C}$ & $\mathrm{A}$ & $\mathrm{B}$ & $\mathrm{C}$ & $\mathrm{B}$ & $\mathrm{A}$ & $\mathrm{A}$ & $\mathrm{B}$ & $\mathrm{A}$ & $\mathrm{A}$ & $\mathrm{B}$ & $\mathrm{B}$ & $\mathrm{C}$ & $\mathrm{B}$ & $\mathrm{C}$ \\
\hline $\mathrm{A}$ & $\mathrm{A}$ & $\mathrm{A}$ & $\mathrm{C}$ & $\mathrm{C}$ & $\mathrm{A}$ & $\mathrm{B}$ & $\mathrm{A}$ & $\mathrm{C}$ & $\mathrm{D}$ & $\mathrm{B}$ & $\mathrm{D}$ & $\mathrm{C}$ & $\mathrm{C}$ & $\mathrm{A}$ \\
\hline $\mathrm{C}$ & $\mathrm{B}$ & $\mathrm{C}$ & $\mathrm{B}$ & $\mathrm{B}$ & $\mathrm{C}$ & $\mathrm{A}$ & $\mathrm{B}$ & $\mathrm{D}$ & $\mathrm{D}$ & $\mathrm{D}$ & $\mathrm{D}$ & $\mathrm{C}$ & $\mathrm{B}$ & $\mathrm{C}$ \\
\hline C & A & A & B & B & B & A & C & B & C & B & C & B & B & A \\
\hline B & B & B & B & B & B & B & A & C & C & C & B & A & B & B \\
\hline B & A & A & A & D & B & A & B & B & B & B & C & B & A & B \\
\hline D & A & A & B & C & C & A & C & C & C & C & B & B & B & B \\
\hline B & B & A & A & C & B & B & B & D & B & D & D & A & A & D \\
\hline
\end{tabular}

According to table 1 and the correlation coefficient between the various indicators, build the correlation coefficient matrix, the size of the absolute value of correlation coefficient reflects the comprehensive evaluation index and index of the original close degree, finally, the relationship between degrees of size as the basis, screened indicators. The results are shown in table 2.

Tab. 2 relationship between the degrees of comprehensive evaluation index as the original indicators

\begin{tabular}{ccccccccccccccc}
\hline $\mathrm{X} 1$ & $\mathrm{X} 2$ & $\mathrm{X} 3$ & $\mathrm{X} 4$ & $\mathrm{X} 5$ & $\mathrm{X} 6$ & $\mathrm{X} 7$ & $\mathrm{X} 8$ & $\mathrm{X} 9$ & $\mathrm{X} 10$ & $\mathrm{X} 11$ & $\mathrm{X} 12$ & $\mathrm{X} 13$ & $\mathrm{X} 14$ & $\mathrm{X} 15$ \\
\hline 0.58 & 0.65 & 0.38 & 0.15 & 0.73 & 0.08 & 0.26 & 0.56 & 0.03 & 0.20 & 0.10 & 0.48 & 0.75 & 0.63 & 0.52 \\
\hline
\end{tabular}

\section{Correlation analysis of B3}

Selection in this paper, Hohhot、Yinchuan、Taiyuan、Changchun、Guangzhou 、 Kunming and so on six different cities as the reference sample, analysis of the urban infrastructure construction, a forestation and ecological environment index statistics. Then classifying the raw data, expressed as: $\mathrm{B} 3=\{\mathrm{Y} 1, \mathrm{Y} 2 \cdots \mathrm{Y} 14\}=$ water $\}$ quality qualified rate, infrastructure pipe $\cdots$ Sewage treatment rate $\}$, classification results as shown in table 3 .

Tab.3 Target classification results

\begin{tabular}{cccccc}
\hline First class & Second class & Third class & Fourth class & Fifth class \\
\hline Y1, Y5, Y9, Y6 & Y3, Y13 & Y2, Y8, Y7, Y10 & Y4, Y11 & Y12, Y14
\end{tabular}

The correlation analysis of every index in Table 3 is carried out, and the formula is [7]:

$$
R^{2}=\frac{\sum_{k=1}^{n}\left(Z_{k i}-\overline{Z_{i}}\right)\left(Z_{k i}-\overline{Z_{j}}\right)}{\sum_{k=1}^{n}\left(Z_{k i}-\overline{Z_{i}}\right)^{2}\left(Z_{k i}-\overline{Z_{j}}\right)^{2}}
$$

Among them: $i=1,2,3 \ldots m, j=1,2,3 \ldots m, i \neq j$. Set a threshold value A, if $M(0<M<1)$, you can delete one of the indicators; if $R_{i j}>M$, while retaining both the index, after the results are shown in Table 4. 
Table 4

\begin{tabular}{ccccc}
\hline Serial number & \multicolumn{2}{c}{ Index } & Correlation coefficient & Processing Method \\
\hline 1 & Y1 & Y5 & 0.758 & Delete Y5 \\
2 & Y9 & Y6 & 0.836 & Delete Y9 \\
3 & Y3 & Y13 & 0.746 & Delete Y13 \\
4 & Y2 & Y8 & 0.862 & Delete Y2 \\
5 & Y7 & Y10 & 0.755 & Delete Y7 \\
6 & Y4 & Y11 & 0.839 & Delete Y11 \\
7 & Y12 & Y14 & 0.905 & Delete Y14 \\
\hline
\end{tabular}

After expert screening process after indicators, statistical screening process, the original 57 Garden City index streamline 22. The new system is more comprehensive index, basically primaries instead of important information system, covering all aspects of the construction of the garden city, has a high representative and reliability.

\section{Conclusion}

In order to respond to and improve the "urban disease" epidemic of recent years, domestic cities have been carrying out activities to create a national garden city. Existing national garden city evaluation criteria used mainly qualitative evaluation, not comprehensive and objective reflection of the quality of green space and the ecological environment construction, the lack of standardized evaluation basis, making scientific and accurate and authoritative evaluation results are affected. In this paper, based on existing standards, subjective and objective, qualitative and quantitative methods, including the initial construction of green space quantity, the quality of green space, municipal infrastructure and environmental construction, including the evaluation of national garden city index system, and screened by experts, after statistical screening, the final evaluation system to build a national garden city, garden city named for the state to provide a new basis.

\section{References}

[1] $\mathrm{Wu}, \mathrm{J}$ G. Effects of changing scale on landscape patter analysis: sealing relations [J]. Landscape Ecology, 2004, 19(2):125-138

[2] Paseua-Horta L, Saura S. Impact of spatial scale on the identification of critical habitat patches for the maintenance of landscape connectivity [J]. Landscape and Urban Planning, 2007, 83:176-186.

[3] Xu Y N, Jia D P, Wang X. The study of green space system planning based on AHP and GIS in Changzhou city, China [C], In:2009 $2^{\text {nd }}$ International Conference on Information and Computing Science, Manchester, United kingdom, 2009, 405-408.

[4] Itziar D A, María F S, Pedro A, et al. Modeling of landscape changes derived from the dynamics of socio-ecological systems: A case of study in a semiarid Mediterranean landscape. Ecological Indicators, 2008, 8(5): 672-685

[5] Patrício J, Ulanowicz R, Pardal M A, et al. Ascendency as an ecological indicator: a case study of estuarine pulse eutrophication, Estuarine. Coastal and Shelf Science,2004, 60(5): 23-35

[6] Howarth R B, Father S. Accounting for the value of ecosystem services.Ecological Economics, 2002, 41(3): 421-429

[7] Simon U, Bruggemann R, Pudenz S. Aspects of decision support in water managementexample Berlin and Potsdam (Germany) I-spatially differentiated evaluation. Water Research, 2004, 38(7): 1809-1816. 